\title{
Effect of Minor Elements on Microstructure and Mechanical Properties
}

\author{
of In 718 Alloy
}

Shouren Guo, Wenru Sun, Dezhong Lu, Zhuangqi HU

Institute of Metal Research, Shenyang 110015, China

\begin{abstract}
The effects of minor elements, $\mathrm{P}, \mathrm{S}$ and $\mathrm{Si}$, on microstructure and mechanical properties of In 718 alloy were investigated. It is shown that decreasing $\mathrm{P}$ content causes the appearance of a film-like $\delta$ phase, while increasing Si content promotes the formation of Laves and $\mathrm{M}_{6} \mathrm{C}$ phases and reduction of the precipitation of $\delta$ phase. The most striking effect is that the stress rupture life prolonged nearly 4 times and the stress rupture ductility rose over 4 times when the $\mathrm{P}$ content increased from $0.0008 \%$ to $0.013 \%$. This remarkable changes of the properties are related to the precipitation and oxidation resistance on the grain boundaries of the alloy. The mechanisms by which $\mathrm{P}, \mathrm{S}$ and Si influence the superalloy are discussed in the text.
\end{abstract}

Superalloys $718,625,706$ and Various Derivatives Edited by E.A. Loria 


\section{Introduction}

To study the role of minor elements in superalloys has been attracted great interest and there have been many results. P, S and Si are generally regarded as detrimental elements and have been strictly restricted. The upper limits of $\mathrm{P}, \mathrm{S}$ and $\mathrm{Si}$ contents have been set lower and lower in most specifications. In fact, the limits of some elements are lack of reasonable proofs. For example, the information about the role of $\mathrm{P}$ in superalloy is very insufficient in literatures. Especially recent works have demonstrated that increasing the $\mathrm{P}$ content can significantly improve the stress rupture property of some superalloys ${ }^{[1,2]}$. To further ascertain the roles of $\mathrm{P}, \mathrm{S}$ and $\mathrm{Si}$ in superalloys, their effects on microstructure and mechanical properties of In 718 alloy has been studied.

\section{Experimental Procedure}

The materials were prepared in a vacuum induction furnace using high purity raw materials. To minimize the compositional variations among the heats, the master alloy was prepared, and its composition (wt-\%) is: Ni 53.19, $\mathrm{Cr} 19.07$, Mo 3.04, Al 0.53, Ti 1.05, Nb 5.03, C 0.029, B 0.0055, and Fe bal.. Then the master alloy was remelted to give nine $12 \mathrm{Kg}$ ingots, in which different contents of $\mathrm{P}, \mathrm{S}$ and $\mathrm{Si}$ were added and only one element was changed in every ingot. The analyzed levels of $\mathrm{P}, \mathrm{S}$ and $\mathrm{Si}$ are given below (wt-\%): P 0.0008, P 0.0035 , P 0.0051 , P 0.0074 , P 0.013 , P 0.049; S 0.0033, S 0.013, S 0.053; Si 0.024 , Si 0.35 . The nine ingots were forged to $35 \mathrm{~mm}$ square bars, then homogenized for $12 \mathrm{~h}$ at $1200{ }^{\circ} \mathrm{C}$ and rolled to $18 \mathrm{~mm}$ round bars at $1120{ }^{\circ} \mathrm{C}$. Specimen blanks were cut from $18 \mathrm{~mm}$ rolled bars, and subjected to the standard heat treatment as follows: $965{ }^{\circ} \mathrm{C} / 1 \mathrm{~h}$, air cooled; $720{ }^{\circ} \mathrm{C} / 8 \mathrm{~h}$, furnace cooled to $620{ }^{\circ} \mathrm{C} ; 620{ }^{\circ} \mathrm{C} / 8 \mathrm{~h}$, air cooled.

Tensile properties were measured at room temperature and $650{ }^{\circ} \mathrm{C}$. Stress rupture tests were performed at $650{ }^{\circ} \mathrm{C}$ at constant stress level of $690 \mathrm{MPa}$. The microstructure was examined by optical and transmission electron microscope (TEM). The phase identification was carried out by using selected area electron diffraction (SAED) and X-ray diffraction. Microzone composition was measured by means of electron microprobe (EMPA) and X-ray energy dispersive spectroscopy (EDAX).

\section{Results and Discussion}

\section{Effect of $\mathrm{P}, \mathrm{S}$ and $\mathrm{Si}$ on the microstructure}

Under the optical observation, the $\mathrm{P}$ and $\mathrm{S}$ contents have no effects on the microstructure of the alloys. Most of rod-like phases precipitate on the grain boundary and a small amount in the grains. With the rise of Si level, the grain size grows slightly up, and blocky or cudgel shape phases are present on the grain boundaries (Fig.1). It is shown that the rod-like phase is $\delta-\mathrm{Ni}_{3} \mathrm{Nb}$ in the 
alloys with addition of $\mathrm{P}$. The blocky and cudgel shape phases on the grain boundaries are mainly $\mathrm{M}_{6} \mathrm{C}$ and Laves in the $0.35 \% \mathrm{Si}$ alloy. The addition of $\mathrm{P}$ obviously affects the form of $\delta$ phase. In the $0.0008 \% \mathrm{P}$ alloy, the $\delta$ phase frequently possesses a highly faulted internal structure $^{[3]}$, and tends to precipitate as a film-like morphology (Fig.2a). With the increase of $\mathrm{P}$ content, the faulted internal structure gradually diminishes and the lath-like $\delta$ phase prefers to precipitate on the grain boundaries (Fig. $2 \mathrm{~b}$ ). In the $0.35 \% \mathrm{Si}$ alloy, most of Laves and $\mathrm{M}_{6} \mathrm{C}$ phases precipitate on the grain boundaries with sharp angles (Fig.3), and hence the amount of $\delta$ phase was reduced.
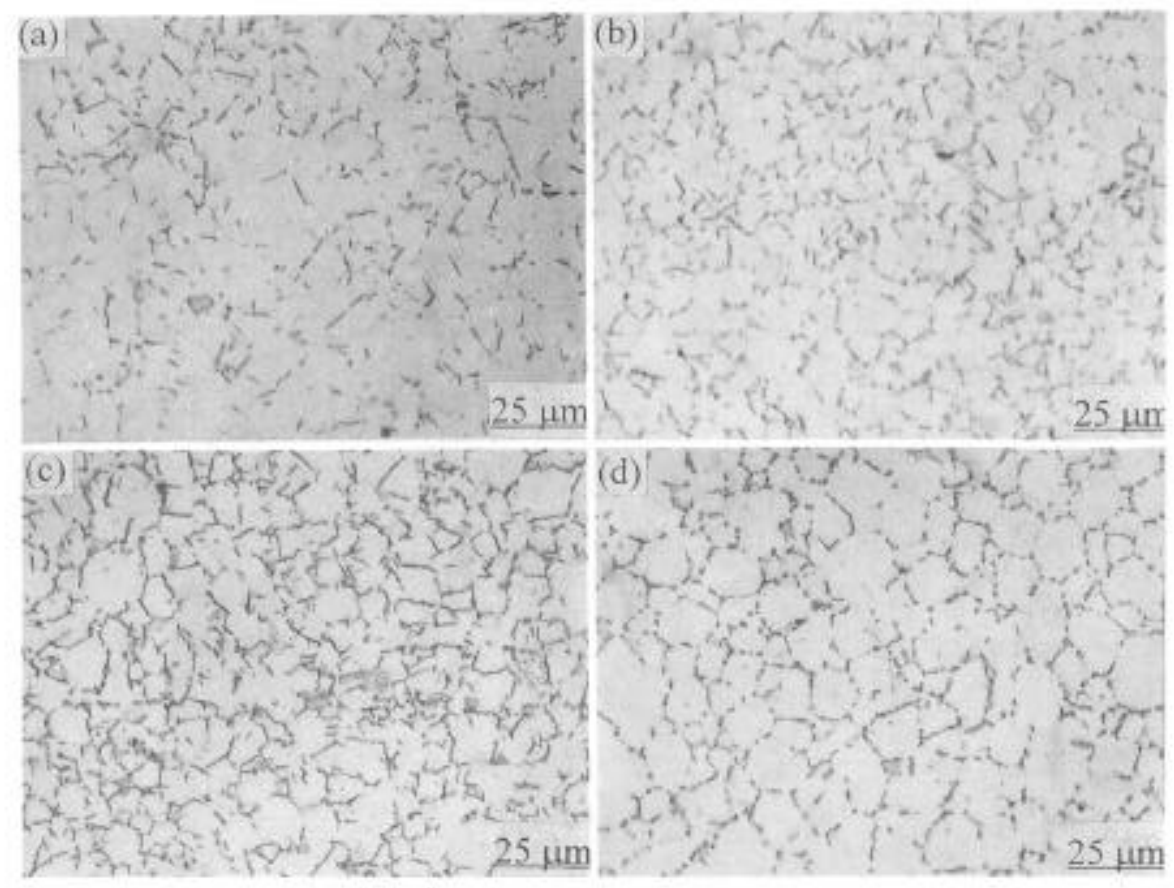

Figure 1-Effect of $\mathrm{P}, \mathrm{S}$, and $\mathrm{Si}$ on the microstructure of In 718 alloy (a) $0.0008 \% \mathrm{P}$, (b) $0.049 \% \mathrm{P}$, (c) $0.053 \% \mathrm{~S}$, (d) $0.35 \% \mathrm{Si}$
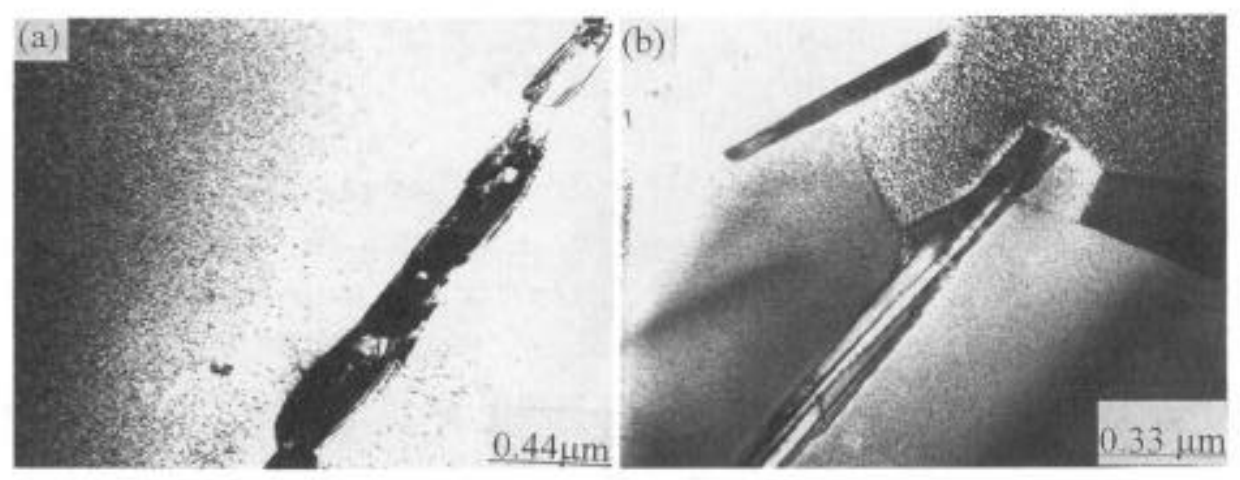

Figure 2-Morphology of grain boundary $\delta$ phase

(a) $0.0008 \% \mathrm{P}$, (b) $0.049 \% \mathrm{P}$ 

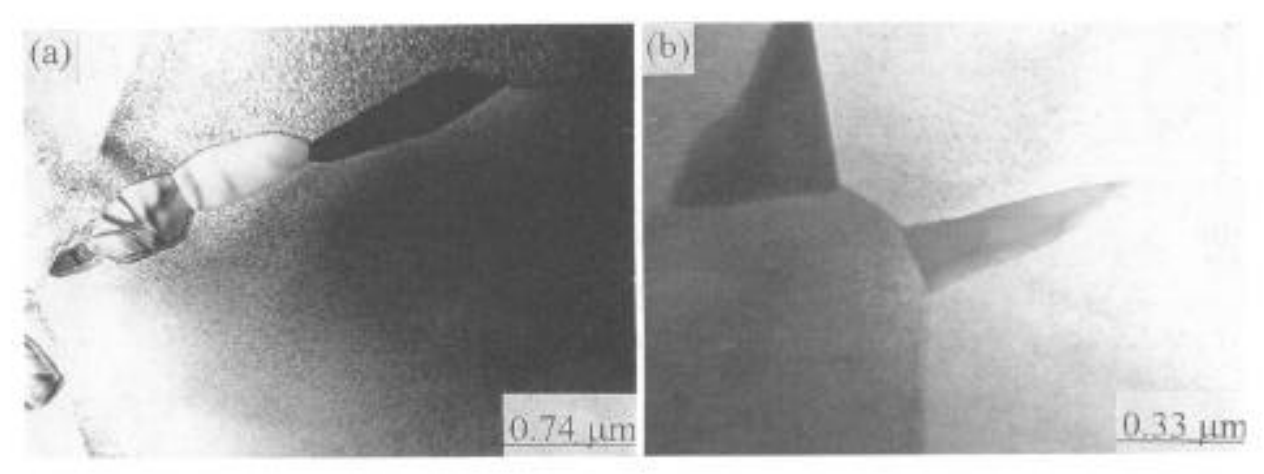

Figure 3-Morphology of Laves (a) and $\mathrm{M}_{6} \mathrm{C}$ (b) phases on the grain boundary of $0.35 \% \mathrm{Si}$ alloy

The segregation of $\mathrm{P}$ on the grain boundary markedly influences the morphology of $\delta$ phase. With the increase of the $\mathrm{P}$ addition, on the one hand, as the grain boundary free energy decreases with the segregation of $\mathrm{P}^{[4]}$, the critical radius of $\delta$ stable embryo is lessened, i.e. $\delta$ embryo much easily nucleates on the grain boundary, and on the other, the probability of forming $\delta$ phase nucleus is reduced as the $\delta$ phase is free of $\mathrm{P}$, so the nucleation of $\delta$ phase becomes much difficult at the grain boundaries, and the effect of the latter exceeds of the former. Overall, the nucleation of $\delta$ phase at the grain boundaries decreases with the $\mathrm{P}$ content. In the $0.0008 \% \mathrm{P}$ alloy, the number of the $\delta$ phase nuclei is large and the distance between the nuclei is shortened at certain local places, leading to the appearance of the film-like $\delta$ phase morphology. On the contrary, in the alloy with a high $\mathrm{P}$ addition, the $\delta$ phase nuclei are less and hence can grow into relatively long lath shape.

The segregation of $\mathrm{Si}$ at the grain boundary also markedly affects the precipitation of grain boundary phases. The Si content of the primary Laves phase $(1.48 \%)$ in the $0.35 \% \mathrm{Si}$ alloy is higher than that of matrix $(0.17 \%)$. After the homogenizing treatment, the primary Laves phase is completely eliminated and the composition of the alloys is basically homogeneous. The Si content in the matrix increases with the dissolution of the Laves phase. This causes more severe lattice strain and results in a large driving force to diffuse $\mathrm{Si}$ in the grain boundary. After thermomechanical processing and heat treatment, the $\mathrm{Si}$ diffuses into the grain boundary and reaches a new equilibrium segregation. With an increase of $\mathrm{Si}$ addition, the segregation of $\mathrm{Si}$ at the grain boundary is enhanced. The $\delta$ phase with a low Si content does not easily nucleate, but the Laves and $\mathrm{M}_{6} \mathrm{C}$ phases with a high $\mathrm{Si}$ content easily nucleate at the grain boundary. Therefore, most of Laves and $\mathrm{M}_{6} \mathrm{C}$ phases are preferentially precipitated at the grain boundary, but the $\delta$ phase is restrained. 


\section{Effect of $\mathrm{P}, \mathrm{S}$ and $\mathrm{Si}$ on the mechanical properties}

Tensile properties As shown in Fig.4, the $\mathrm{P}$ has similar effects on the tensile properties at room temperature and $650{ }^{\circ} \mathrm{C}$. When the $\mathrm{P}$ content raises, the tensile strength changes little, only the strength slightly decreases when the $\mathrm{P}$ content is $0.049 \%$, but the tensile ductility increases small, especially the reduction of area at $650{ }^{\circ} \mathrm{C}$ enhances markedly and reaches a peak value at $0.013 \% \mathrm{P}$. The effect of $\mathrm{P}$ on the tensile properties closely relates to the precipitation of $\delta$ phase. The formation of the film-like $\delta$ phase favors crack propagation, so the tensile ductility lowers when the $\mathrm{P}$ content is quite low. With rise of $\mathrm{P}$ content, the $\delta$ phase gradually changes into lath-like, the ductility improves. Because the transformation of $\delta$ phase is even more notable at the grain boundary, it has still greater effect on $650{ }^{\circ} \mathrm{C}$ tensile ductility, at which the fracture is intergranular.

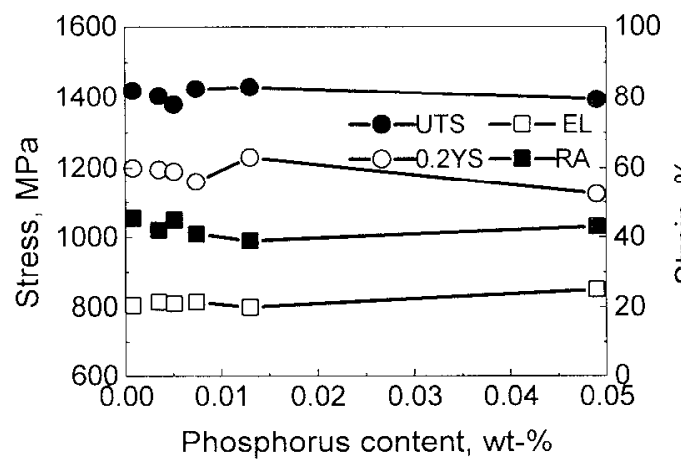

(a) At room temperature

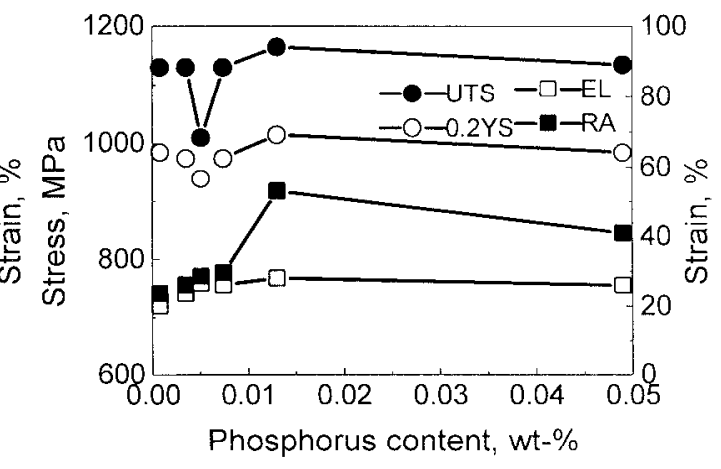

(b) At $650^{\circ} \mathrm{C}$

Figure 4-Effect of $\mathrm{P}$ on the tensile properties of In 718 alloy

The Si content has no obvious effect on the tensile strength at room temperature and $650{ }^{\circ} \mathrm{C}$, but the tensile ductility has a falling tendency, especially the reduction of area reduces faster (Fig.5). It is attributed to the formation of Laves and $\mathrm{M}_{6} \mathrm{C}$ phases in the high $\mathrm{Si}$ alloy. The effects of $\mathrm{S}$ on the tensile properties at room temperature and $650{ }^{\circ} \mathrm{C}$ are shown in Fig.6. When the alloys contain less than $0.013 \%$, the strength decreases, but the ductility at room temperature increases. Further raising the $\mathrm{S}$ content, the strength increases, but the ductility decreases. When the $\mathrm{S}$ content reaches $0.053 \%$, they return to original level. The ductility at $650{ }^{\circ} \mathrm{C}$ changes little with the S content. 


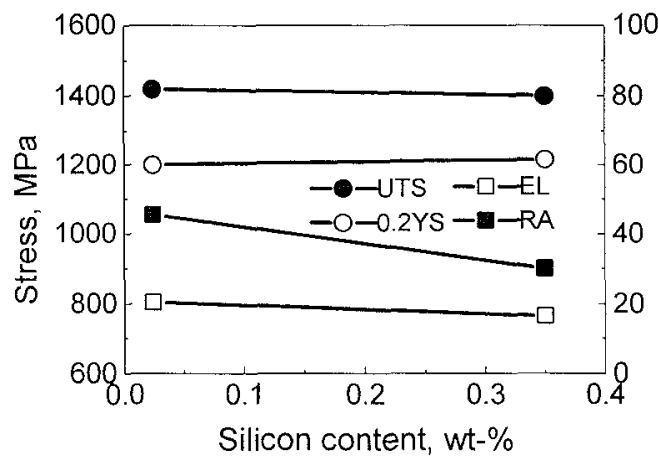

(a) At room temperature

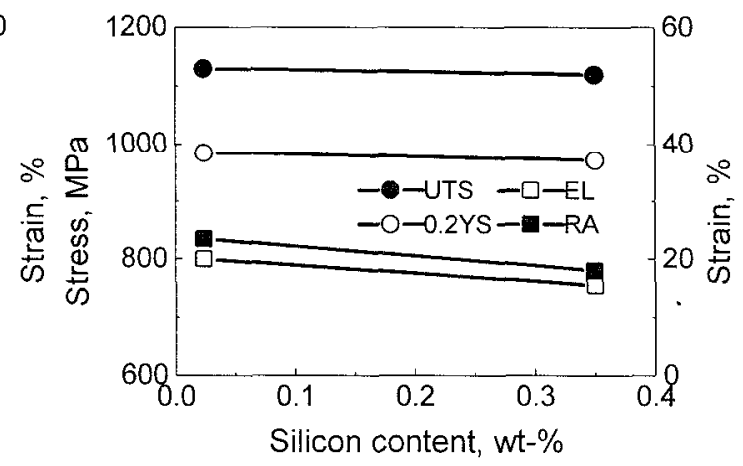

(b) At $650^{\circ} \mathrm{C}$

Figure 5-Effect of $\mathrm{Si}$ on the tensile properties of In 718 alloy

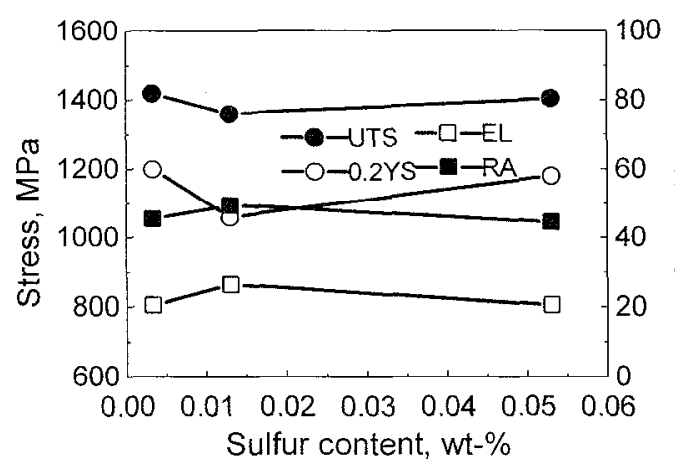

(a) At room temperature

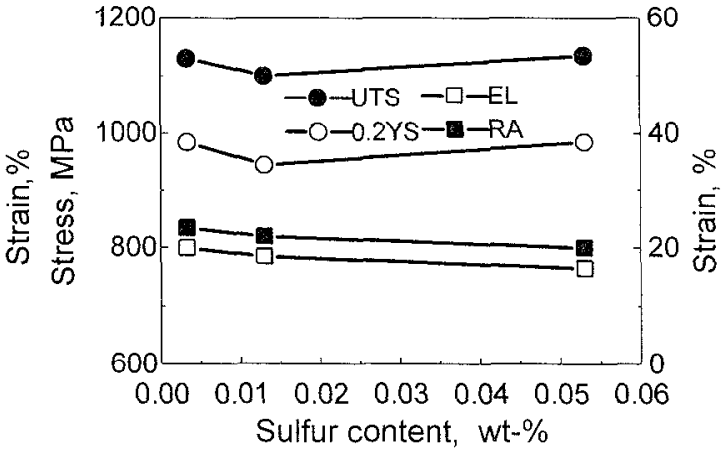

(b) At $650^{\circ} \mathrm{C}$

Figure 6-Effect of S on the tensile properties of In 718 alloy

Stress rupture properties The effects of $\mathrm{P}$ on stress rupture properties are shown in Fig.7. Both the stress rupture life and the stress rupture ductility. reach peak values at about $0.013 \% \mathrm{P}$. In the $0.013 \% \mathrm{P}$ alloy, the stress rupture life and the ductility are $420 \mathrm{~h}$ and $27.2 \%$ respectively, 4 times more than those of the $0.0008 \% \mathrm{P}$ alloy. The stress rupture life and the ductility of $0.049 \% \mathrm{P}$ alloy are not less than those of $0.0008 \% \mathrm{P}$ alloy. $\mathrm{S}$ and $\mathrm{Si}$ have no notable effects on the stress rupture propertics in the range tested (Fig.8). 


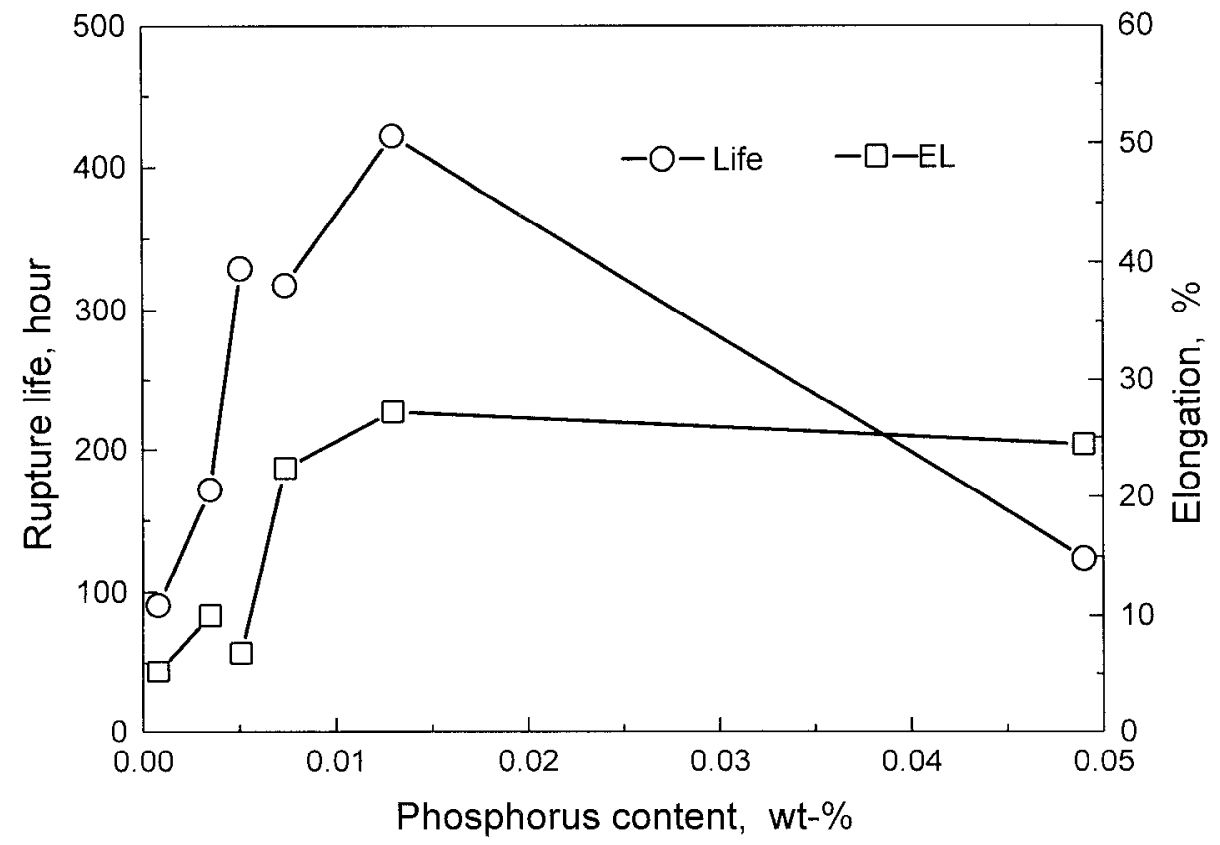

Figure 7-Effect of $\mathrm{P}$ on the stress rupture properties of In 718 alloy at $650{ }^{\circ} \mathrm{C}, 690 \mathrm{MPa}$
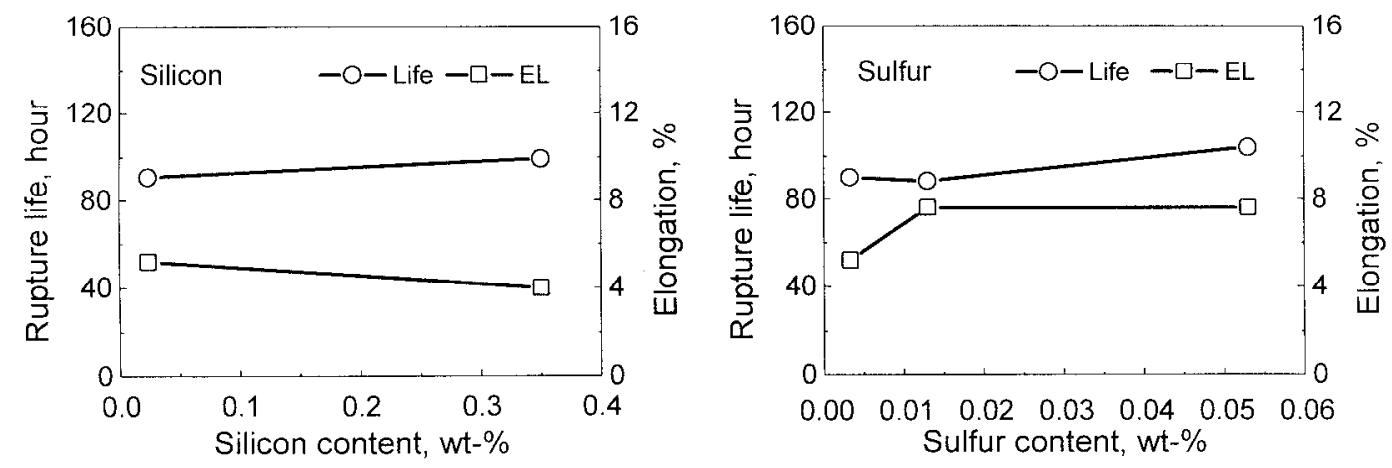

Figure 8-Effect of $\mathrm{Si}$ and $\mathrm{S}$ on the stress rupture properties of $\operatorname{In} 718$ alloy at $650{ }^{\circ} \mathrm{C}, 690 \mathrm{MPa}$ 
The overall features of the fracture surface of the alloys modified with $\mathrm{P}$ are shown in Fig.9. The cracks are initiated on the grain boundary and propagated intergranularly, finally broken in a transgranular mode. Obviously, the stress rupture properties are determined by initiation and propagation of intergranular cracks. When the P content is $0.0008 \%$, the crack is initiated on the surface of specimen, then quickly propagated. The intergranular fracture exhibits a "river" pattern. As the P content increases to $0.013 \%$, the intergranular crack exists in the surface and inside of specimen, but the rate of crack propagation is quite slow. When the $\mathrm{P}$ content is $0.049 \%$, the crack is initiated at the inside of specimen, then propagated toward the surface of specimen, and the fracture is smooth. The tendency of oxide formation at the exposed grain boundary is large when the $\mathrm{P}$ content is $0.0008 \%$. The amount of the oxides at the grain boundary drops with the $\mathrm{P}$ content and notable oxides were not observed when the $P$ raises to $0.049 \%$ (Fig. 10 ).

It can be seen that the changes of the $\delta$ phase and the oxidation resistance at the grain boundary with the $\mathrm{P}$ content are probably the primary factors of the influence of $\mathrm{P}$ on the stress rupture properties. In the alloy containing $0.0008 \% \mathrm{P}$, as the $\delta$ phase is film-like and the oxidation resistance is lower, so the crack easily initiates at oxidized grain boundary and quickly propagates intergranularly under the tensile stress. The crack propagation accelerates the penetration of oxygen, which makes the binding force of the grain boundary reduce. Therefore, the fracture shows river pattern. By EMPA analysis, it is found that $\mathrm{P}$ is greatly depleted in the oxides on the grain boundary. When the $\mathrm{P}$ content increases, the high segregation of $\mathrm{P}$ on the grain boundary prevents
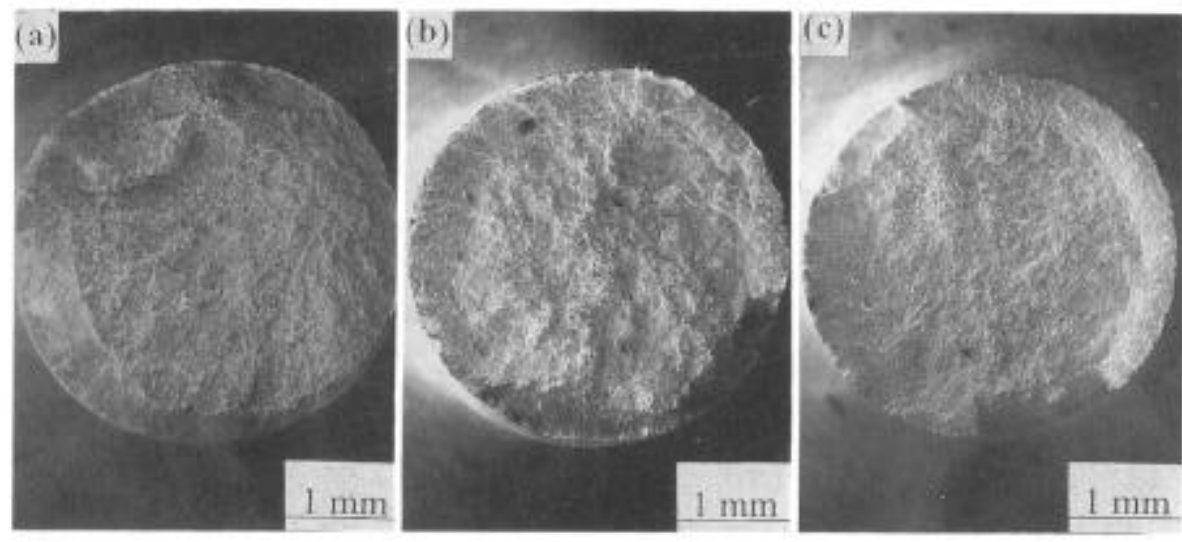

Figure 9-Fractography of the stress rupture specimens of In 718 alloy
(a) $0.0008 \% \mathrm{P}$
(b) $0.013 \% \mathrm{P}$
(c) $0.049 \% \mathrm{P}$ 


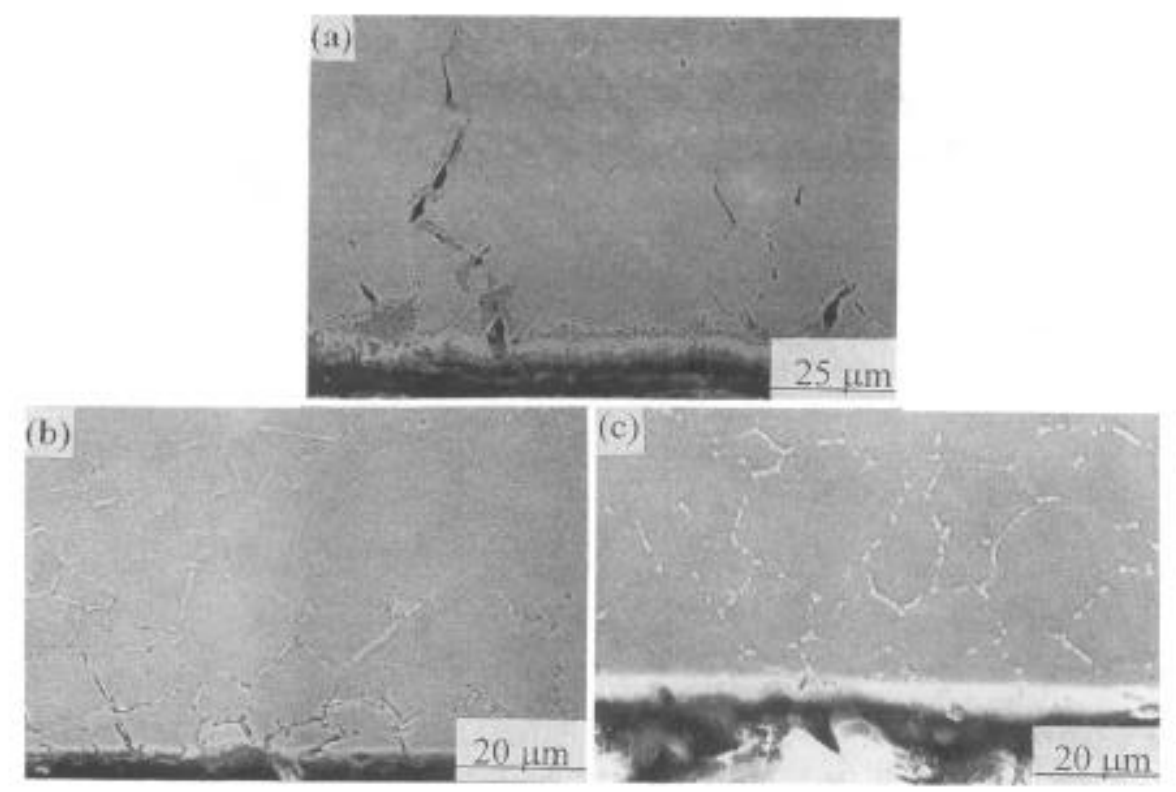

Figure 10-Effect of $\mathrm{P}$ and $\mathrm{Si}$ on the formation of oxide at the grain boundary (a) $0.0008 \% \mathrm{P}$, (b) $0.049 \% \mathrm{P}$, (c) $0.35 \% \mathrm{Si}$

the diffusion of oxygen, greatly decreases the formation rate of the oxides at the grain boundary, so the oxidation is restricted. And the film-like $\delta$ phase gradually diminishes, and the lath-like $\delta$ phase prefers to precipitate on the grain boundary with the $\mathrm{P}$ content. Therefore, when the $\mathrm{P}$ content goes up, the stress rupture life and the ductility increase and reach peak value at the $0.013 \%$ P. Further increasing P level to $0.049 \%$, although the oxidation at the grain boundary is restrained, excessive segregation of $\mathrm{P}$ probably changes the structure of grain boundary and weakens the coherence of grain boundary ${ }^{[5]}$. The crack initiates inside the specimen and quickly propagates. The fracture is smooth.

When the Si content raises from $0.024 \%$ to $0.035 \%$, some harmful Laves and $\mathrm{M}_{6} \mathrm{C}$ phases are precipitated on the grain boundary and the amount of $\delta$ phase is decreased, but the oxidation resistance is raised (Fig.10c), and the stress rupture property does not drop. $\mathrm{S}$ has no effect on the morphology of the grain boundary precipitates, so it has no pronounced influence on the stress rupture property of the alloys. 


\section{Conclusion}

1. The P content has notable effect on the morphology of $\delta$ phase. In the alloy containing $0.0008 \% \mathrm{P}$, the $\delta$ phase tends to precipitate as the film-like and the $\delta$ phase gradually changes into the lath-like with the $\mathrm{P}$ content.

2. When the Si content raises, the formation of intergranular Laves and $\mathrm{M}_{6} \mathrm{C}$ phases increases and hence the precipitation of $\delta$ phase reduces.

3. The tensile strength changes little with the $\mathrm{P}$ and $\mathrm{Si}$ contents, and the $\mathrm{P}$ raises the tensile ductility, especially the ductility at $650{ }^{\circ} \mathrm{C}$ has a maximum value at $0.013 \% \mathrm{P}$, but the $\mathrm{Si}$ reduces the tensile ductility. With the increase of $\mathrm{S}$ content, the tensile strength has a low value, but the ductility changes little.

4. $\mathrm{P}$ content strikingly raises the stress rupture life and the stress rupture ductility of the alloy. When the $\mathrm{P}$ content is $0.013 \%$, the stress rupture life and the ductility reach the peak value. The beneficial effect of $P$ is derived from the improvements of precipitation and oxidation resistance of the grain boundary. S and Si have no noticeable effect on the stress rupture properties.

\section{References}

1. W. R. Sun, S. R. Guo, D. Z. Lu, and Z. Q. Hu, Metall. Trans., 27A (1996)

2. W. D. Cao and R. L. Kennedy: in "Superalloys 718, 625, 706 and Various Derivatives," Ed. by E. A. Loria, (TMS-AIME, Warrendale PA, 1994), 463477

3. M. G. Burke and M. K. Miller, in "Superalloys 718, 625 and Various Derivatives," Ed. by E. A. Loria, (TMS-AIME, Warrendale PA, 1991), 337 350

4. J. T. Wang, Q Chen, and G. S. Li, Acta Metall. Sinica, 21 (1985), 477-484 (in Chinesc)

5. W. G. Hartweck and H. J. Grabake, Acta Metall., 29 (1981), 1237-1246 